\title{
Correction to: Precision Therapy for Brain Tumors in Hereditary Syndromes
}

\author{
Gerald C. Wallace, $M D^{1}$ \\ Madeleine Tjoelker, $M S^{2}$ \\ Kaitlyn Bartley, PharmD ${ }^{3}$ \\ John W. Henson, $M D^{4, *}$
}

\author{
Address \\ ${ }^{1}$ Neurology Residency Program, Medical College of Georgia, 1120 15th Street, Augusta, \\ GA 30912, USA \\ ${ }^{2}$ Hereditary Cancer Clinic, Georgia Cancer Center, Medical College of Georgia, Augusta \\ University, 1411 Laney Walker Blvd, Augusta, GA 30912, USA \\ ${ }^{3}$ Georgia Cancer Center, Medical College of Georgia, Augusta University, 1411 Laney \\ Walker Blvd, Augusta, GA 30912, USA \\ *,4Georgia Neurofibromatosis Clinic, Brain Tumor Program and Hereditary Cancer Clinic, \\ Georgia Cancer Center, Medical College of Georgia, Augusta University, 1411 Laney \\ Walker Blvd, Augusta, GA 30912, USA \\ Email: johenson@augusta.edu \\ Published online: 20 August 2021 \\ ๑ Springer Science+Business Media, LLC, part of Springer Nature 2021
}

The original article can be found online at https://doi.org/10.1007/s11864-021-00876-7.

Correction to: Curr. Treat. Options in Oncol. 22:80 (2021) https://doi.org/10.1007/s11864-021-00876-7

In the original version of this article, the author name, Gerald C. Wallace, was incorrectly written as Gerald E. Wallace. The original article has been corrected.

\section{Publisher's Note}

Springer Nature remains neutral with regard to jurisdictional claims in published maps and institutional affiliations. 